\title{
Epistemic Modality and Projection in Argumentative Writing: A Corpus-driven Comparison of Chinese English Majors and Native English Speakers
}

\author{
Demei Yang \\ School of Foreign Languages, Southwest Jiaotong University, Chengdu, China \\ Xiangmin Zeng \\ School of Foreign Languages, Southwest Jiaotong University, Chengdu, China
}

\begin{abstract}
In academic writings, writers are supposed to properly express the degree of certainty and doubt. Especially in the argumentative text, writers are required to give appropriate arguments and project previous theories or ideas. Epistemic modality and projection are concerned with how writers express their degree of certainty and doubt, which is important for a qualified argumentative text writer. Through comparison of 30 pieces of argumentative essays respectively from Chinese English majors and native English speakers of undergraduate level, this study finds that Chinese English majors rely more on a narrower and imbalanced epistemic devices and projecting verbs in their writings. Therefore, it's imperative for Chinese English majors to expand their vocabulary and improve their English proficiency.
\end{abstract}

Index Terms - projection, epistemic modality, argumentative writing, second language learner

\section{INTRODUCTION}

For students at the tertiary level, writing is deemed as one of the most important academic skills (Vandenhoek, 2018). Writing in a foreign language is difficult for second language learners (Hinkel, 1997; Reid, 2002; Warschauer, 2010). Among the different writing genres, argumentative writing is most challenging and a major problem is to convey statements with an appropriate degree of doubt and certainty (Hyland \& Milton, 1997; Luna, Villalón, Mateos \& Martín, 2020). Authors need to distinguish the opinions from facts or other people, evaluating their assertions in acceptable and persuasive ways. As such, the ability to express doubt and certainty properly is a task of quite complexity but importance. Unfortunately, the expression of doubt and certainty in a suitable degree has long turned out to be troublesome for the writers, especially for those nonnative academic novices.

Epistemic modality is concerned with writers or speakers' evaluation of possibilities and the degree of confidence in what they write or say, or commitment to the truth and their statements (Coates, 1983; Quirk, Greenbaum, Leech, \& Svartvik, 1985). It's very important for writers to make statements with the precise degree of certainty or doubt, which requires the writers to master a variety of epistemic devices of the target language. However, researches have evidenced that it's quite difficult for second language learners to make statements with an appropriate degree of certainty and uncertainty (Allison, 1995; Hyland \& Milton, 1997; McEnery \& Kifle, 2002).

Another perspective of understanding the writer's certainty and doubt is through projection. When authors are writing, in addition to proposing questions and making claims, they also need to find fit-in facts, statistics, or theories to support their assertions. As Thompson (2004) points out, in looking into projection in text, certain threads emerge as particularly worth investigating, and "there is a question of the reporter's attitude toward what is reported" (p.215). That is to say, Thompson believes that the content which the reporter projects is to a large extent decided by his or her intention, but as for the extent to which the reporter agrees with the content and how readers or listeners tell the reporter's attitude, we can find something from the reporter's consideration of the reporting verbs and sources. And a message is either positive or negative, but semantically, there are also intermediate stages, which are between the two polars (yes and no), such as "maybe" or "supposedly" which are expressed by modality.

Since the epistemic modality and projection are the two parallel ways of understanding writer's expressing of certainty and doubt, yet little research has combined the two phenomena appearing simultaneously in an argumentative writing. This study hence attempts to discuss the two facets based on corpora of native and nonnative English speakers. Specifically, the present study attempts to compare the writers' expression of doubt and certainty in argumentative essays of both native English speakers (NES) and Chinese English majors (CEM) of undergraduate level. Through such comparison, the result would provide reflection or reference for second language learners' writing and educators' teaching. 


\section{EPISTEMIC ModAlity AND PRoJeCtion IN TEXT}

\section{A. Epistemic Modality}

Modality is quite important in academic written discourse as it conveys the writer's attitude to readers (Yang, 2018). Simply stated, modality is the space between "yes" and "no" (Thompson, 2004). Modality can be typically divided into two basic types: epistemic modality and root modality (Halliday, 1994; Hyland, 1994; Hoye, 1997). Epistemic modality is a means of conveying the degree of a speaker's or writer's commitment to the truth of what is being asserted. In argumentative writing, writers usually express modality lexically through epistemic modality devices. Traditional model verbs (or model auxiliaries), for instance, can, could, may, might, will, would, shall, should, etc. are often regarded as the realization of epistemic modality. However, other lexical verbs (e.g., believe, infer, think, infer), adjectives (e.g., definite, possible, probable, certain), adverbs (e.g., probably, possibly, indeed, certainly), nouns (e.g., possibility, doubt, belief, assertion) and some units and expressions (e.g., chances are, it seems) are also used to express certainty and doubt.

TABLE 1

FIVE CATEGORIES OF EPISTEMIC MODALITY

\begin{tabular}{ll}
\hline \hline Categories & Examples \\
\hline a. Certainty & certainly, actually, indeed, in fact, know, think, will, etc. \\
b. Probability & believe, probably, quite, seem, would, etc. \\
c. Possibility & may, might, perhaps, possible, possibly, etc. \\
d. Usuality & always, often, usually, etc. \\
e. Approximation & about, almost, approximately, etc. \\
\hline
\end{tabular}

According to Hyland \& Milton (1997), the devices of epistemic modality can be divided into five general categories as in Table 1. This categorization has some difference from the types of modality in Systemic Functional Grammar. For instance, Thompson (2004) introduces that there are two basic types of modality (modalization and modulation) on the basis of the information, goods-and-services. However, it has been accepted and examined useful by researchers (Holmes, 1983, 1988; Haliday, 1994; McEnery \& Kifle, 2002; Oh, 2007, etc.)

When it comes to a second language learner's expression of epistemic modality, it is necessary to understand certainty and doubt of different extent. For instance, the epistemic modality devices in category of Certainty indicate that the writer asserts with certainty that the statement is true or not true, devices in category of Probability indicate that the statement is probably true, while devices in category of Possibility indicate that the writer asserts his statement is possibly true or possibly not true. In a word, the writer's assertive degree of statement in three categories is approximately shown as: Certainty > Probability > Possibility.

(1) I'm quite certain that the reform is beneficial to the regional development.

(2) Learning a second language is quite important for a contemporary college student.

(3) It might well be adopted by other localities.

The three utterances above provide a simple example that epistemic modality users express certainty and likelihood of different degree. Utterance (1) expresses the writer's certainty about the validity of statement, while utterances (2) and (3) express the writer's estimate that the statements are probably and possibly true. In this way, utterance (1) clearly carries more certainty than (2) and (3), and (3) indicates less certainty than (2).

\section{B. Projection in Text}

Halliday (1994) defines projection as "a kind of logical-semantic relationship whereby a clause comes to function not as a direct representation of experience but as a representation of a representation" (p.250). In general, projection is an important concept in SFG to describe a linguistic phenomenon: quote or restate what other people said and thought. In the projection clause complex, the content of the projected clause can be the verbal events as well as the mental events. The verbal events are locutions while the mental events are ideas or thoughts. Thompson (2004) points out that in the case of projecting ideas, since the thinking goes on inside someone's mind, there is no original wording, and the expression choice is open to us.

"Speak English," said Carrie. (locution)

"She's nobody's fool," I thought. (Idea)

When projecting locutions, it's projecting verbally while projecting mentally is projecting ideas. Both the two kinds of projection can be recognized by the different projecting verbs, for instance in Table 2.

TABLE 2

TYPES OF PROJECTING VERBS

\begin{tabular}{ll}
\hline \hline Types & Examples \\
\hline Locution projecting & say, tell, require, point out, report, remark, observe, ask, query, insist, complain, \\
Idea projecting & warn, shout, stammer, murmur, etc. \\
think, believe, feel, reckon, hope, expect, suppose, expect, suspect, imagine, etc.
\end{tabular}


The projecting verbs listed above are far from being exhausted, and due to the genre and text difference, the projecting verbs vary from one to another. The present study focuses on English learners' argumentative essays, and the projecting verbs may be exemplified different from projecting verbs in other texts.

Thompson (1996) interprets projection from the perspective of discourse. He postulates that there are four dimensions of choices in projecting language events: voice, message, signal, and attitude. Thompson (2004) discusses further that the "reporter's attitude and the projecting source are the threads that emerge as particularly worth investigating" (p.215). The projecting verbs carry the reporter's attitude, for instance, 'point out' indicates that the reporter accepts what the other person said as true, while the projecting verb 'claim' suggests that the reporter's doubt and skepticism. Since there is a relative freedom for us to operate projecting language expression, the reporter's decision and attitude thus should be taken into consideration.

\section{RESEARCH DESIGN}

\section{A. Research Questions}

Inspired by Thompson's perspective of projection in text, the present study intends to explore further the projection phenomenon in English learners' argumentative essays combining with epistemic modality. Considering that English learners in universities are a large group employing English, and argumentative writing, a combination of argument, proofs, facts, and personal ideas, is a relatively ideal text for doing such research, the present study attempts to explore how projection and modality are embodied in their writing, and how projection and modality show the writers' attitude when students are doing argumentative essays. To make the study more objective and significant, the study focuses on both CEMs' and NESs' essays. To be more specific, the present study will answer the following two questions.

Q1: What is the feature of the projecting verbs and modality devices used in CEM and NES corpora?

Q2: Is there any significant difference between CEM and NES in employing modality and projection?

\section{B. The Two Corpora}

The data in the present study includes 30 CEMs' argumentative essays and 30 NESs' argumentative essays. The CEM are students majoring in English at a university in southwest China, and NESs' essays are from the Michigan Corpus of Upper-level Student Papers (MICUSP). MICUSP, a corpus launched by the Corpus Research Group at the University of Michigan's English Language Institute, provides graded papers written by University of Michigan students, and covers a wide range of disciplines and text-type or genres.

In the present study, the essays from both CEMs and NESs are written by the students of the final year of undergraduate. The reason why the present study centers on the academic essays of final-year undergraduate students is that, the crucial tasks for undergraduate English learners are to acquire language ability and prepare for the academic studies in their postgraduate stage. Therefore, their employments of epistemic modality devices and projection to express adequately can to a large extent be used to examine their studies and then are of concern. After the data collection, the author builds two separate sub-corpora: CEM and NES.

TABLE 3

SIZE OF THE CORPORA

\begin{tabular}{llll}
\hline \hline Corpora & Size (bytes) & Word Tokens & Word Type \\
\hline CEM & 415,079 & 65,924 & 6,974 \\
NES & 436,554 & 70,368 & 7,811 \\
\hline
\end{tabular}

From Table 3, it can be seen that the sizes of CEM and NES are quite close and balanced, thus the following discussion and comparison can be carried on. To build two separate corpora is to observe whether there is a significant difference between NES and CEM in terms of employing projection and modality.

\section{Procedures}

In each corpus, the title, abstract, and reference part are excluded. All the files are converted to "txt" form with a common coding of UTF-8. After that, a computer software Antconc is utilized to index. Antconc is widely applied by researchers to conduct corpus studies and provides researchers with the function of words and phrases indexing. In the present study, it is mainly utilized to index the projecting verbs and epistemic modality devices in clause complexes. In total, 82 projecting verbs and 120 epistemic modality devices are examined in the study on the basis of the previous studies. It should be pointed out that some modality devices overlap with the projecting verbs. For example, think, hope, feel, believe, consider, imagine, etc. in the study work as both idea projecting verbs and modality devices. In addition, the present study discusses projection in clause complex level, and not all the results indexed out meet the requirement. For instance, in general, there are about three forms for each projecting verb and some of them may not function as verbs, which requires manual operation to get rid of the noun form. For instance, the verb think, when being imputed into Antconc, has three forms: think, thinks, and thought, in Antconc, and the word form thought can also index out the forms of have/has/had thought as well as the noun form. Another typical kind of situation requiring manual operation is the verb functions as a name. Here lists some examples:

a. "he or it had the power to try to suppress or prevent that act or thought." (NES13.txt) 
b. "Said defines Orientalism in three dimensions, as an academic discipline, as a style of thought based on binary distinction between the Occidentand the Orient, and the corporate institution that deals with the Orient." (NES5.txt)

c. "At that time, although the United States had broken apartheid in law, in fact apartheid still existed in the South." (CEM19.txt)

\section{RESULTS AND DisCUSSIONS}

This part presents comparative indexing results of epistemic devices and projecting verbs in the two corpora before conducting a general discussion.

\section{A. The Usage of Epistemic Modality in the Two Corpora}

Hyland \& Milton (1997) provide a list of most frequent epistemic items including 77 items compiled from a lot of researchers and scholars (e.g., Holmes, 1983 \& 1988; Quirk et al., 1972, etc.). Korean scholar Oh (2007) extends the list to 110 items. The present study examined the 120 items in the two corpora. (see Appendix A)

TABLE 4

OVERALL FREQUENCY OF THE EPISTEMIC MODALITY DEVICES

\begin{tabular}{lll}
\hline \hline & CEM & NES \\
\hline Total number & 2066 & 2976 \\
Tokens per 100 words & 3.1 & 4.2 \\
Top 10 items & $1116(54.0 \%)$ & $1344(45.2 \%)$ \\
Top 20 items & $1460(71.1 \%)$ & $1935(65.0 \%)$ \\
\hline
\end{tabular}

From Table 4, Chinese English majors use fewer epistemic modality devices in their argumentative writings than native English speakers. However, both the top 10 and top 20 items of devices in Chinese English majors have respectively higher frequency than those of native English students, which indicates that CEM students' writings contain a more restricted range and higher frequency of using epistemic modality devices than the NES students'.

TABLE 5

TOP TEN MOST FREQUENT EPISTEMIC MODALITY DEVICES

\begin{tabular}{lllll}
\hline \hline & CEM & & NES & \\
\hline Rank & Epistemic Items & Frequency & Epistemic Items & Frequency \\
\hline 1 & can & 315 & would & 203 \\
2 & will & 146 & seem & 167 \\
3 & about & 111 & will & 165 \\
4 & should & 107 & can & 164 \\
5 & think & 91 & may & 109 \\
6 & view & 66 & should & 97 \\
7 & know & 62 & fact & 92 \\
8 & need & 60 & claim & 91 \\
9 & may & 53 & about & 86 \\
10 & actually & 53 & idea & 86 \\
\hline
\end{tabular}

When exploring in depth the specific epistemic modality devices use, some similarities in the two corpora as in Table 5 can be observed. For instance, the common items most frequently used by both CEM and NES students are: can, will, about, should, may. The five items appear on the two lists, but their frequencies are not the same, e.g., the item about appears in CEM for 111 times but 86 in NES. Despite this kind of difference, it is more distinctive that some words (e.g., think) do not appear in native English speakers' expressions of certainty. Therefore, the Chinese English majors' use of epistemic modality device in argumentative writing tends to be more informal and subjective. 


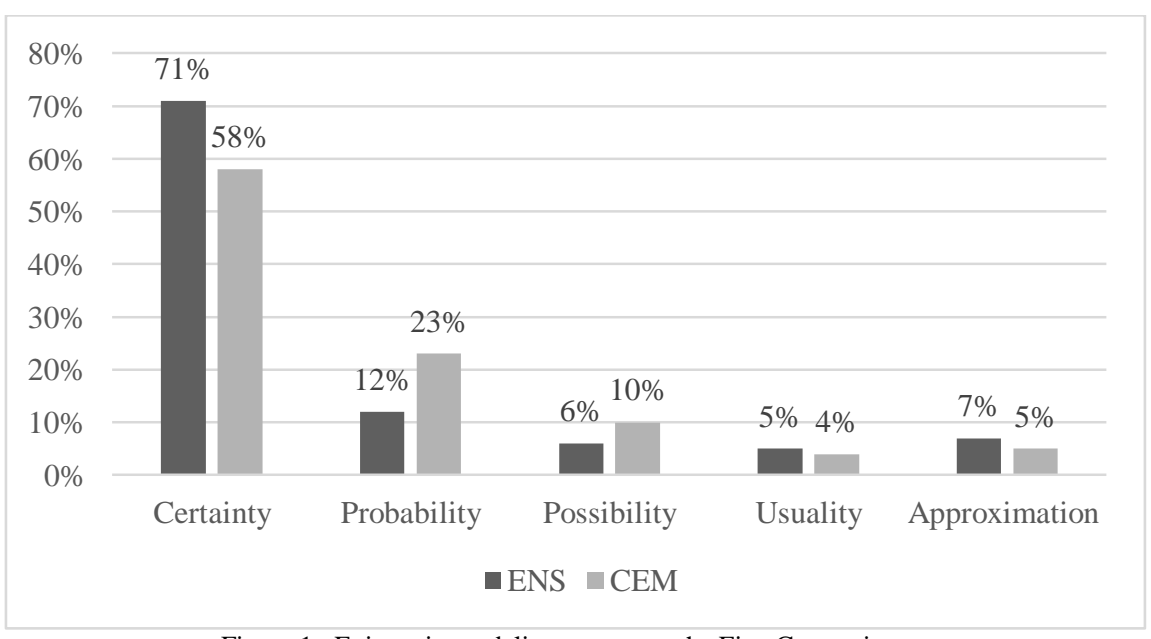

Figure 1 Epistemic modality use across the Five Categories

From Figure 1 above, it can be easily seen that in argumentative writings, both native English speakers and Chinese English majors employ much more certainty than tentativeness. However, Chinese English majors tend to express likelihood than native English speakers.

\section{B. The Usage of Projections in the Two Corpora}

By means of Antconc, projection clause complexes are indexed out through imputing the projection markers, especially the projecting verbs. Halliday (2000) points out that there must be a projecting verb or a nominalization of the projecting verb in the projection clause complex. And Thompson's perspective of studying projection in text shows us that in different genres and texts, the commonly used verbs change. For example, in narrative writings, the projection verbs can be more vivid and diverse, e.g., murmur, shout, stammer, etc. However, when it comes to academic writings, there would be academic discourse and formality consideration, hence the choice of the projecting verbs is quite different, e.g., propose, point out, claim, announce, etc. Due to the differences of commonly used projecting verbs in different texts, the author combines the features of both argumentative and academic writing, and concludes 55 commonly used projecting verbs which project locutions (verbal events) and 27 ideas (mental events).

TABLE 6

DISTRIBUTIONS OF PROJECTING VERBS AFTER MANUAL OPERATION

\begin{tabular}{llll}
\hline \hline Corpora & Projecting verbs & Frequency & Percentage \\
\hline \multirow{2}{*}{ CEM } & Locution & 423 & $0.64 \%$ \\
& Idea & 407 & $0.62 \%$ \\
\multirow{2}{*}{ NES } & Locution & 652 & $0.93 \%$ \\
& Idea & 479 & $0.68 \%$ \\
\hline
\end{tabular}

After manual operation, in Table 6, it can be seen that in terms of the frequency of projecting verbs, both locution projecting and idea projection in CEM are higher than those in NES. In particular, in locution projection, NES which takes $0.93 \%$ is obviously higher than $0.64 \%$ of CEM. But we cannot draw a conclusion that there is a significant difference between the two corpora, and thus more specific and detailed projecting verbs need to be explored.

TABLE 7

TOP TEN MOST FREQUENT PROJECTING VERBS

\begin{tabular}{|c|c|c|c|c|}
\hline & CEM & & NES & \\
\hline Rank & Projecting verbs & Frequency & Projecting verbs & Frequency \\
\hline 1 & think & 91 & find & 81 \\
\hline 2 & say & 91 & say & 80 \\
\hline 3 & view & 66 & claim & 79 \\
\hline 4 & want & 62 & state & 79 \\
\hline 5 & find & 59 & think & 68 \\
\hline 6 & show & 54 & believe & 58 \\
\hline 7 & Regard & 35 & view & 55 \\
\hline 8 & believe & 34 & consider & 44 \\
\hline 9 & tell & 32 & show & 37 \\
\hline 10 & Recognize & 19 & Tell & 37 \\
\hline Total & $543(0.82 \%)$ & & $618(0.88 \%)$ & \\
\hline
\end{tabular}

From Table 6, the total frequency of the top ten projecting verbs is quite close, and in general, their preferences of projecting verbs are quite similar. Seven words appear in both top-ten lists: think, say, view, find, show, believe, tell. However, when the list extends, the difference tends to be more obvious: the frequency of projecting verbs in NES 
$(1251,1.78 \%)$ is higher than that in CEM $(776,1.2 \%)$, and apparently, CEM students employ a narrower range of the projecting verbs (see Appendix B).

\section{General Discussion and Implications}

The four years of undergraduate is quite important for English learners to accumulate language ability and prepare for academic writings. It is of vital importance for them to make clear the proper usages of modality devices and projecting verbs to express appropriately in their writings. However, from the statistics obtained in the present study, it is still a challenge for these Chinese English majors to master the epistemic modality devices and projecting verbs in their writings. There are various reasons why these second language learners might find it a difficult competence to acquire.

Firstly, the first language competence inevitably exerts an impact on the second language acquisition. L1 competence ideally involves a wide range of knowledge repertoire that people use to communicate appropriately for multiple purposes in their communities, whereas second language competence is usually or inevitably more restricted for the reason that the second language serves a more limited range of communicative needs than the first language, especially when the second language learners reside in their native language communities. Secondly, the second language learning purposes give different priorities for second language use. According to Saville-Troike (2006), in considering the purposes for which a person needs to learn a second language, there are two types of fundamental communicative competence: academic competence and interpersonal competence. The two types of competence focus differently on the skills of reading, speaking and writing. For instance, learning second language for academic purpose gives more priorities to reading and writing competence while interpersonal purpose gives more priorities to listening and speaking. Thirdly, the cultural difference also makes an impact on the second language learner's preference of vocabulary. Having been accustomed to communication in a high context culture, Chinese people tend to express their ideas in a more mild and euphemistic way, which leads their expression in English less assertive than those learners under a low context culture.

The comparison of uses of the epistemic modality and projecting verbs with native English speakers unveils the Chinese English majors' shortage and lower diversity of the vocabulary in their argumentative writings. Second language learners need to develop the ability to express the degree of their commitment to their assertions and convey their attitudes to their readers when they are writing. Therefore, it is urgent for the second language learners to improve their language proficiency.

From a pedagogical perspective, students should expand the range of their epistemic devices, try various types of different categories to accurately and fully express a degree of certainty and doubt in their writings. In addition, specifying the register of written and spoken text can also help the appropriate expression in their writings. In addition, attention should be paid to the cultural difference between native language and the second language communities. Teachers could cultivate students' second language competence according to their learning purposes and encourage students to improve their writing skills through the input of extensive reading of native works.

\section{CONCLUSIONS}

In academic writings, writers are supposed to use appropriate devices to express the degree of certainty and doubt. Especially in the argumentative text, writers need to make a statement and then illustrate it with evidence, which requires the author to give proper arguments and project previous theory or ideas. This study explored the argumentative essays from Chinese English majors and native English speakers of undergraduate level from the perspective of epistemic modality and projection. The results indicated that Chinese English majors contain a narrower range of both projecting verbs and epistemic modality devices and make less balanced use of them than native English students. In addition, Chinese English majors tend to write in a more assertive tone with stronger certainty than native English students. Through the comparison, Chinese English majors are clearer about their shortages and are expected to expand their vocabulary and improve second language proficiency. This study has limitations as the size of the two corpora is not large enough. Larger corpora could be used to test the findings in this study, and the in-depth usage difference can be discussed in the future studies. 
APPENDix A. EPISTEMic ModAlity DeVICES AND FREQUENCIES

\begin{tabular}{|c|c|c|c|c|}
\hline & NES & & CEM & \\
\hline & Devices & Frequency & Devices & Frequency \\
\hline 1. & can & 315 & would & 203 \\
\hline 2. & will & 146 & will & 165 \\
\hline 3. & should & 107 & can & 164 \\
\hline 4. & need & 60 & may & 109 \\
\hline 5. & may & 53 & should & 97 \\
\hline 6. & would & 36 & must & 84 \\
\hline 7. & must & 35 & need & 58 \\
\hline 8. & could & 34 & could & 54 \\
\hline 9. & have to & 31 & might & 38 \\
\hline 10. & can't & 27 & would not & 19 \\
\hline 11. & could not & 16 & have to & 18 \\
\hline 12. & should not & 11 & should not & 16 \\
\hline 13. & dare & 8 & shall & 12 \\
\hline 14. & might & 6 & may not & 11 \\
\hline 15. & would not & 4 & could not & 5 \\
\hline 16. & may not & 4 & can't & 4 \\
\hline 17. & couldn't & 3 & might not & 2 \\
\hline 18. & won’t & 2 & won't & 1 \\
\hline 19. & shall & 1 & dare & 0 \\
\hline 20. & had better & 1 & couldn't & 0 \\
\hline 21. & might not & 0 & had better & 0 \\
\hline 22. & shall not & 0 & shall not & 0 \\
\hline 23. & needn't & 0 & needn't & 0 \\
\hline 24. & mustn't & 0 & mustn't & 0 \\
\hline 25. & think & 91 & seem & 167 \\
\hline 26. & know & 62 & claim & 79 \\
\hline 27. & believe & 34 & think & 68 \\
\hline 28. & appear & 30 & believe & 58 \\
\hline 29. & feel & 29 & argue & 53 \\
\hline 30. & seem & 29 & consider & 44 \\
\hline 31. & hope & 15 & feel & 34 \\
\hline 32. & doubt & 15 & know & 29 \\
\hline 33. & consider & 9 & assume & 23 \\
\hline 34. & expect & 6 & appear & 22 \\
\hline 35. & tend & 6 & expect & 16 \\
\hline 36. & suppose & 6 & tend & 12 \\
\hline 37. & imagine & 5 & suppose & 10 \\
\hline 38. & claim & 4 & indicate & 10 \\
\hline 39. & guess & 4 & propose & 10 \\
\hline 40. & indicate & 4 & doubt & 7 \\
\hline 41. & predict & 3 & imagine & 7 \\
\hline 42. & assume & 2 & hope & 4 \\
\hline 43. & estimate & 2 & guess & 1 \\
\hline 44. & argue & 1 & predict & 1 \\
\hline 45. & propose & 1 & estimate & 1 \\
\hline 46. & presume & 0 & presume & 1 \\
\hline 47. & speculate & 0 & speculate & 1 \\
\hline 48. & about & 111 & about & 86 \\
\hline 49. & always & 40 & often & 35 \\
\hline 50. & often & 11 & perhaps & 34 \\
\hline 51. & never & 21 & actually & 32 \\
\hline 52. & In fact & 39 & never & 29 \\
\hline 53. & actually & 53 & always & 28 \\
\hline 54. & clearly & 4 & indeed & 25 \\
\hline 55. & generally & 20 & clearly & 24 \\
\hline 56. & usually & 10 & almost & 24 \\
\hline 57. & naturally & 36 & In fact & 23 \\
\hline 58. & around & 16 & generally & 18 \\
\hline 59. & relatively & 0 & necessarily & 18 \\
\hline 60. & sometimes & 14 & usually & 15 \\
\hline 61. & perhaps & 13 & around & 13 \\
\hline 62. & almost & 6 & likely & 13 \\
\hline 63. & maybe & 2 & probably & 12 \\
\hline
\end{tabular}




\begin{tabular}{|c|c|c|c|c|}
\hline 64. & of course & 1 & presumably & 12 \\
\hline 65. & In reality & 13 & relatively & 10 \\
\hline 66. & definitely & 1 & certainly & 10 \\
\hline 67. & obviously & 0 & possibly & 10 \\
\hline 68. & surely & 6 & surely & 9 \\
\hline 69. & likely & 12 & sometimes & 7 \\
\hline 70. & indeed & 8 & of course & 7 \\
\hline 71. & undoubtedly & 2 & largely & 6 \\
\hline 72. & in X's opinion & 1 & In general & 6 \\
\hline 73. & commonly & 1 & essentially & 6 \\
\hline 74. & probably & 14 & naturally & 5 \\
\hline 75. & frequently & 3 & in X's opinion & 5 \\
\hline 76. & apparently & 2 & frequently & 5 \\
\hline 77. & inevitably & 8 & in reality & 4 \\
\hline 78. & largely & 7 & obviously & 4 \\
\hline 79. & certainly & 7 & definitely & 3 \\
\hline 80. & In general & 2 & inevitably & 3 \\
\hline 81. & normally & 9 & maybe & 2 \\
\hline 82. & not always & 2 & apparently & 2 \\
\hline 83. & essentially & 0 & in theory & 2 \\
\hline 84. & presumably & 0 & plainly & 2 \\
\hline 85. & rarely & 3 & commonly & 1 \\
\hline 86. & necessarily & 1 & normally & 1 \\
\hline 87. & approximately & 1 & not always & 1 \\
\hline 88. & doubtless & 1 & rarely & 1 \\
\hline 89. & In theory & 4 & undoubtedly & 0 \\
\hline 90. & plainly & 0 & approximately & 0 \\
\hline 91. & possibly & 0 & doubtless & 0 \\
\hline 92. & evidently & 0 & evidently & 0 \\
\hline 93. & a certain extent & 0 & a certain extent & 0 \\
\hline 94. & view & 66 & fact & 92 \\
\hline 95. & fact & 52 & claim & 91 \\
\hline 96. & idea & 22 & idea & 86 \\
\hline 97. & opinion & 19 & view & 55 \\
\hline 98. & hope & 15 & explanation & 27 \\
\hline 99. & doubt & 15 & evidence & 17 \\
\hline 100. & chance & 8 & possibility & 15 \\
\hline 101. & possibility & 4 & opinion & 14 \\
\hline 102. & claim & 4 & doubt & 12 \\
\hline 103. & evidence & 4 & certainty & 9 \\
\hline 104. & explanation & 3 & assumption & 7 \\
\hline 105. & danger & 2 & hope & 5 \\
\hline 106. & assumption & 0 & chance & 5 \\
\hline 107. & certainty & 0 & danger & 4 \\
\hline 108. & estimate & 0 & estimate & 1 \\
\hline 109. & clear & 17 & clear & 73 \\
\hline 110. & certain & 16 & certain & 49 \\
\hline 111. & possible & 13 & sure & 44 \\
\hline 112. & inevitable & 13 & possible & 42 \\
\hline 113. & obvious & 13 & likely & 20 \\
\hline 114. & likely & 6 & obvious & 14 \\
\hline 115. & sure & 5 & apparent & 8 \\
\hline 116. & plain & 5 & unlikely & 7 \\
\hline 117. & evident & 1 & evident & 6 \\
\hline 118. & unlikely & 0 & plain & 2 \\
\hline 119. & apparent & 0 & inevitable & 0 \\
\hline 120. & probable & 0 & probable & 0 \\
\hline
\end{tabular}


ApPendix B. Frequency of Projecting Verbs in the Corpora

\begin{tabular}{|c|c|c|c|c|}
\hline & NES & & CEN & \\
\hline Rank & Projecting verbs & Frequency & Projecting verbs & Frequency \\
\hline 1 & think & 91 & find & 81 \\
\hline 2 & say & 91 & say & 80 \\
\hline 3 & view & 66 & claim & 79 \\
\hline 4 & want & 62 & state & 79 \\
\hline 5 & find & 59 & think & 68 \\
\hline 6 & show & 54 & believe & 58 \\
\hline 7 & regard & 35 & view & 55 \\
\hline 8 & believe & 34 & consider & 44 \\
\hline 9 & tell & 32 & show & 37 \\
\hline 10 & recognize & 19 & tell & 37 \\
\hline 11 & speak & 18 & explain & 35 \\
\hline 12 & hold & 16 & define & 32 \\
\hline 13 & doubt & 15 & research & 31 \\
\hline 14 & advocate & 15 & discuss & 30 \\
\hline 15 & hope & 15 & hold & 26 \\
\hline 16 & explain & 13 & note & 25 \\
\hline 17 & reveal & 12 & agree & 23 \\
\hline 18 & point out & 11 & suggest & 23 \\
\hline 19 & talk about & 9 & assume & 23 \\
\hline 20 & consider & 9 & regard & 22 \\
\hline 21 & define & 9 & want & 21 \\
\hline 22 & put forward & 7 & speak & 21 \\
\hline 23 & discover & 7 & determine & 20 \\
\hline 24 & suppose & 6 & discuss & 20 \\
\hline 25 & discuss & 6 & assert & 20 \\
\hline 26 & insist & 6 & point out & 16 \\
\hline 27 & note & 5 & conclude & 16 \\
\hline 28 & agree & 5 & expect & 16 \\
\hline 29 & admit & 5 & recognize & 14 \\
\hline 30 & wonder & 5 & illustrate & 12 \\
\hline 31 & suggest & 4 & admit & 11 \\
\hline 32 & suspect & 4 & indicate & 10 \\
\hline 33 & indicate & 4 & propose & 10 \\
\hline 34 & claim & 4 & suppose & 10 \\
\hline 35 & remind & 3 & imagine & 10 \\
\hline 36 & persuade & 3 & reveal & 9 \\
\hline 37 & confess & 3 & discover & 9 \\
\hline 38 & respond & 2 & advocate & 8 \\
\hline 39 & conclude & 2 & confirm & 8 \\
\hline 40 & assume & 2 & doubt & 7 \\
\hline 41 & assert & 2 & perceive & 7 \\
\hline 42 & acknowledge & 2 & suppose & 6 \\
\hline 43 & propose & 1 & persuade & 5 \\
\hline 44 & announce & 1 & discover & 5 \\
\hline 45 & advise & 1 & hope & 4 \\
\hline 46 & repeat & 1 & acknowledge & 4 \\
\hline 47 & & & recommend & 4 \\
\hline 48 & & & wonder & 3 \\
\hline 49 & & & suspect & 3 \\
\hline 50 & & & insist & 3 \\
\hline 51 & & & decide & 3 \\
\hline 52 & & & wonder & 3 \\
\hline 53 & & & suspect & 3 \\
\hline 54 & & & repeat & 3 \\
\hline 55 & & & respond & 2 \\
\hline 56 & & & announce & 2 \\
\hline 57 & & & remark & 2 \\
\hline 58 & & & remind & 1 \\
\hline 59 & & & remind & 1 \\
\hline
\end{tabular}




\section{REFERENCES}

[1] Allison, D. (1995). Assertions and alternatives: Helping ESL undergraduates extend their choices in academic writing. Journal of Second Language Writing, 4, 1-15. Doi: 10.1016/1060-3743(95)90020-9.

[2] Coates, J. (1983). The Semantics of the Modal Auxiliaries. Beckenham: Croom Helm.

[3] Halliday, M. (1994). An Introduction to Functional Grammar. (2nd ed.) London: Edward Arnold.

[4] Halliday, M. A. K., (2000). An Introduction to Functional Grammar (2rd edition). London: Edward Arnold, 331.

[5] Hinkel, E. (1997). Indirectness in L1 and L2 academic writing. Journal of Pragmatics, 27 (3), 361-386. Doi:10.1016/S03782166(96)00040-9.

[6] Holmes, J. (1983). Speaking English with the appropriate degree of conviction. In C. Brumfit (Ed.), Learning and Teaching Languages for Communication: Applied Linguistics Perspective (pp. 100-121). London: CILT.

[7] Holmes, J. (1988). Doubt and certainty in ESL textbooks. Applied Linguistics, 9, 20-44. Doi:10.1093/applin/9.1.21.

[8] Hoye, L. (1997). Adverbs and Modality in English. London: Longman.

[9] Hyland, K. (1994). Hedging in academic writing and EAP textbooks. English for Specific Purposes, 13, 239-256.

[10] Hyland, K., \& Milton, J. (1997). Qualification and certainty in L1 and L2 students' writing. Journal of Second Language Writing, 6(2), 183-205. Doi:10.1016/S1060-3743(97)90033-3.

[11] Luna, M., Villalón, R., Mateos, M., \& Martín, E. (2020). Improving university argumentative writing through an online training. Journal of Writing Research, 12 (1), 233-262. Doi: EDU2013-46606-C2-1-R.

[12] McEnery, T., \& Kifle, N. (2002). Epistemic modality in argumentative essays of second-language writers. In T. Flowerdue (Ed.) Academic Discourse (pp. 182-195). London: Longman.

[13] Oh, S. Y. (2007). A corpus-based study of epistemic modality in Korean college students' writings in English. English Teaching, $62(2), 147-175$.

[14] Quirk, R., Greenbaum, S., Leech, G., \& Svartvik, J. (1985). A Comprehensive Grammar of the English Language. London: Longman.

[15] Reid, J. (2002). Writing. In Ronald Carter and David Nunan (eds). The Cambridge Guide to Teaching English to Speakers of Other Languages (pp. 28-33). Cambridge; Cambridge University Press.

[16] Saville-Troike, M. (2006). Introducing Second Language Acquisition. Cambridge: Cambridge University Press.

[17] Thompson, G. (1996). Introducing Functional Grammar. London: Arnold.

[18] Thompson, G. (2004). Introducing Functional Grammar (2rd edition). London: Arnold.

[19] Vandenhoek, T. (2018). Epistemic markers in NS and NNS academic writing. Journal of Academic Writing, 8 (1), $72-91$. Doi:10.18552/joaw.v8i1.359.

[20] Warschauer, M. (2010). New tools for teaching writing. Language Learning \& Technology, 14 (1), 3-8.

[21] Yang, X. (2018). A Corpus-Based Study of Modal Verbs in Chinese Learners' Academic Writing. English Language Teaching, 11(2), 122-130. Doi: 10.5539/elt.v11n2p122.

Demei Yang was born in Sichuan province, China. She received her bachelor's degree from Southwest Jiao-tong University.

She is currently pursuing a master's degree at Southwest Jiao-tong University, majoring in Foreign Linguistics and Applied Linguistics. Her research interests include Second Language Acquisition, Foreign Language Teaching, and Cross-cultural Communication.

Xiangmin Zeng, associate professor and MA supervisor of English language and literature, is currently teaching at the Department of English, School of Foreign Languages, Southwest Jiaotong University, China. His academic interest includes second language acquisition, cross-cultural communication and European cultural studies. He has published several research articles on such issues in Chinese journals. 